\title{
Digital Learning in Higher Education: A Road to Transformation and Reform
}

\author{
Jabbar Al Muzzamil Fareen ${ }^{1 *}$ (1)
}

${ }^{1}$ PDPM Indian Institute of Information Technology, Design \& Manufacturing Jabalpur, INDIA

*Corresponding Author: jamfareen2006@yahoo.com

Citation: Fareen, J. A. M. (2022). Digital Learning in Higher Education: A Road to Transformation and Reform. European Journal of Interactive Multimedia and Education, 3(1), e02206. https://doi.org/10.30935/ejimed/11493

\begin{abstract}
Digital learning has been the need of the hour as it has been providing access to online resources and to get students engaged in their higher education courses amid COVID-19 lockdown. This paper is focused on highlighting how the Information and Communication Technology (ICT) tools, media and E-pedagogy as an instructional practice have been robustly used to gain disciplinary knowledge and information and to continuously avail the benefits of virtual learning. Higher education has been specifically digitalized and trialled without any preparation on the part of academies as well as teachers and students. This paper is more concerned on understanding how lockdown accelerated the digitalization of higher education and universities positively responded switching on to technology enabled online platforms for both instruction and evaluation. Further, it is also suggested that in the process of shifting to E-Pedagogy, both teachers and students need to be continuously provided with adequate technical tools and media to stay connected in online classes through virtual mode.
\end{abstract}

Keywords: COVID-19, digital learning; e-pedagogy, higher education, Information and Communication Technology (ICT), online learning resources, Knowledge and Resource Management (KRM)

Received: 25 May $2021 \bullet$ Accepted: 21 Nov. 2021

\section{INTRODUCTION}

Digital learning has become a prerequisite factor for acquiring knowledge and to access the amenities of higher education amid COVID-19 nationwide lockdown. As all the students incline to enter colleges and universities to get enrolled into graduation and doctoral research programmes, they consider the possession of ICT tools like smart phones and laptop mandatory to continue into their course. Students can get benefit from the digital libraries and acquire prevalent world knowledge of their disciplines through ICT tools and media. In addition to the text and references available in the institutional library, students are instructed to browse relevant online journals to update required knowledge and information of their discipline. It has been widely emphasized that students need to be sufficiently prepared and trained to use the relevant software applications and updated technology in their devices and should accustomed to learn their subjects through online resources. Surfing through the World Wide Web (WWW) with the search engines like Google Chrome, Firefox, and Internet Explorer has been a routine activity of any tertiary level student. To sustain themselves to be a part of knowledge based society, they supplement their learning with the available online resources and compensate their knowledge with higher order thinking skills (Chang, 2016; Songkram et al., 2015). Thus, given to the prevailing competition found for deeper learning of their subjects, it can be entrusted that students are fairly open to accommodate ICT tools for their academic success and considered it as an essential criterion for their Knowledge and Resource Management (KRM) (Aithal \& Aithal, 2016; Sarkar, 2012).

\section{DIGITALIZATION OF HIGHER EDUCATION AMID COVID-19 - A NEW TRANSFORMATION}

The significant use of ICT tools in digital learning is apparent and could be easily witnessed in this COVID-19 lockdown. When the access to classrooms and conventional learning cannot be exercised in the long run of lockdown period, it is the smart phones and laptops that came to immediate rescue and helped students to secure their further study without any hindrances in the process of their higher education. Elearning, also widely referred as virtual learning was considered as the only alternative for hassle-free pedagogy and evaluation amidst unpredictable phases of nationwide lockdown. All the universities worldwide, irrespective of their limited online resources, unanimously considered that higher education can contemplate with the digitalization of education. When there is a possibility of conducting virtual classes through online conferencing apps like Zoom, Google Meet, Google Classroom, and Webex, there are equal challenges too (Muruthy \& Yamin, 2017; Owusu-Fordjour et al., 2020). As the universities inclined to continue their courses through these online 
platforms, though the teachers and students who are not literally trained to go through E-Pedagogy, are really prepared to face any practical challenges in the due course of their online conduct of classes. Both teachers and students engage in motivating and supporting reached out to one another in the process of E-Pedagogy for the smooth conduct of their courses (Dumford \& Miller, 2018). The digitalization of higher education has been possible only because of the immediate recognition on the part of the academies, teachers and students in using and practicing of E-learning in the testing times of lockdown.

\section{SHIFT TO DIGITAL LEARNING - RISKS, CHALLENGES AND OPPORTUNITIES}

\section{Digital Divide}

The low economic background status remains a hard disposition to the students who cannot afford to buy quality smartphones and laptops with the required features, facilities and applications to undertake their studies through virtual programmes (Delamonica et al., 2004; Meskhi et al., 2019). Due to low wages and unemployment issues in this turbulent phase of lockdown, both the middle and low income group suffered tremendously to procure those ICT tools and resources for digital learning. And also, due to the prolonged financial backwardness and becoming more jobless, the students hailing from underprivileged and marginalized society remain secluded to get into those amenities of digital learning. As economic backwardness happens to be the mainstay of digital divide, it needs to be immediately addressed so that the digitalization of education cannot be easily possible without the practice of ICT tools and resources.

\section{Reluctant Beliefs, Attitudes and Outlook Towards Digital Learning}

The teachers and students who have stern belief in conventional approaches to learning remain hesitant to follow-up with the practice of E-learning (Bonvillian \& Singer, 2013; Ertmer, 2005; Islam et al., 2015). For them, E-Pedagogy remains to be a gap filling phenomena to compensate the regular classes in the COVID-19 lockdown, but it cannot be a permanent alternative to the conventional learning and also, they stubbornly believe that virtual learning cannot replace real classrooms. They consider that it can be an occasional aid, but not a complete solution to replace regular face to face classes. Some teachers are reluctant to upgrade with the modern methods and approaches of learning and hence they seldom use the ICT tools in their courses. Some teachers are eager to take up the mix of both conventional and ICT approaches, but they find hard to get sufficient training and support from their institutes and they personally are not able to spend their time and space to get trained to use the technical aids in the classroom. The knack of mixing both conventional and modern approaches to learning is the need of the hour. The teachers who practice conventional approaches to teaching accept the nuances of ICT tools and the significance of digital learning, but they find it difficult to practice due to the large number of students in their classes. Due to the overcrowded classrooms, they find very hard to monitor the students' interest and involvement in the classes through digital learning.

Teachers generally experience and understand the students' attitude and performances through their body language and the nonverbal cues in the conventional classes, whereas in the digital learning contexts, when the teacher is on presentation, students are asked to be on mute.
Hence, when face to face interactive learning is not permitted in online classes or conferences, attitudes of the students cannot be monitored. To control the overlapping noises in the synchronized interactive and discussion sessions, both teachers and students resume to being more silent on virtual learning sessions. And also, to provide opportunity for one another, they remain monotonous, silent and boring rather than making it livelier as in their conventional classes. The teachers who are techno savvy may be able to confidently use technology as an aid in their teaching, but they should also examine how far the technology is feasible to attain the set learning objectives and how much the students have really benefitted from their technology integrated courses. As the technology enabled learning in higher education is crucial today, both the teachers and students need to self-examine the merits and demerits of the use of integrating technology in the past, present and future (Albirini, 2006; Baporikar, 2016; Bingimlas, 2009; Dumford \& Miller, 2018; Gautam \& Tiwari, 2016; Schoepp, 2005).

\section{USE OF ICT IN ONLINE PEDAGOGY AND EVALUATION}

The most essential feature of technology enabled learning is to amalgamate its presence with the teaching-learning content, process and evaluation. Technology should help the students to gain knowledge, not for seeking knowledge for the sake of knowledge, but should stimulate all the representatives and stakeholders to engage in developing their higher order thinking skills and to indulge in both creative and critical learning skills. Digital learning should accommodate with the psychological, social, educational and humanistic perspectives rather than strictly adhered to the business notions of computer scientists and software service providers. Due to the rapid revolution and ongoing changes happens in information, telecommunication and computer domain technologies, the academic institutions and teachers are on the verge of accommodating those resources. As it may affect more cost consuming, even the central and state owned and aided government institutions are not able to meet to observe those technologies in their courses. Most private institutions also remain backwards due to the lack of required finance and hence they procure and install only those required software, if it is instructed to be mandatory. Mention needs to be made in specific, that there are few private universities which aim at world standards equipping themselves with the grandiose infrastructure and latest technologies in classrooms, seminar halls, digital libraries and laboratories that even the public institutions are not equipped with.

It can be impartially assumed that those teachers who enjoy good infrastructure and fair maintenance of technological resources are able to give their fullest cooperation in assimilating modern trends and technologies in their theoretical and practical approaches to learning. And it can be easily inferred that those tertiary level institutions and teachers are in their receiving end when they are to reform and update with the changing trends of technology. With all these setbacks, higher educational institutions need to equip with ICT tools and media and should instigate both the teachers and students to adopt those modern technologies in education (Sife et al., 2007; Sweeney et al., 2004). Both the teachers and students need to have sufficient knowledge and awareness about the emerging technologies in their field and should be capable enough to adapt to the changing needs of the education and 
industry (Ghavifekr \& Rosdy, 2015; Keller \& Cernerud, 2002; Kocur \& Kosc, 2009; Love \& Fry, 2006; Martin, 2007).

Students should have sufficient knowledge of English to understand the content and features of advanced technologies, and should be able to interact in English with their counterparts in the virtual learning environment. As technology enabled learning has become the most required twenty first century skills in education, knowledge of English and the ability to use English for gaining technical information and professional communication is mandatory. In this new normal, with the formalized setting of virtual classes, both teachers and students are expected to communicate in English and this has proved to be a positive sign where they confidently indulge in interaction. Teachers' presentations are entirely done in English and they provide questionnaire time to respond to the students' enquiries. To exchange necessary information, chatting in the classes is done in English. The formalized informal style can be found in the online chatting and the WhatsApp text messages and in the subsequent correspondences through emails. Due to the sharing of online recordings of the classes, students are much benefitted to listen and watch the power point presentation as many times as they wish and could concretely understand the given concepts in the online lectures. It could be acknowledged that technology is a blessing in disguise as it helps the students listening, reading and speaking skills in English and to develop their content based language learning abilities through online.

The efficacy of online education rests with the narrow angled idealistic view of education which serves to connect more with the human-machine interface rather than the human-human interface. Social interaction activities are at high-stake due to the online learning environment. In the present contexts of new normalcy, higher education students had no regrets to report on the use of smartphones based online learning. The possession of the smartphone as a technical tool by every student has helped higher educational institutions to carry on their course instruction through these devices (Almaiah et al., 2019). As all the students are not afforded to possess a computer or laptop at home, the only feasible device that they are entrusted to personal and educational use is smartphones (Sarrab et al., 2013). The most recognized areas of concern are their accessibility and affordability to get internet connectivity and the problems connected with it and when they are not making out to any, it happens to be a disaster. Both teachers and students undergo low internet connectivity problems and frequently face technical barriers with the incompatible features of electronic devices or the lack of inbuilt software and required technologies in their old devices. They generally undergo with technological apprehension problems as they frequently encounter in waiting for the document or websites to open and close, unable to switch from one app to the other app, unable to upload or download the required files, converting one file format to another, frequent malfunctioning of the devices and unable to connect for conferences in the time bound presentations. This obstructs to instantly execute their functional duties.

In the long run of the use of ICT and media tools, the skills to integrate technology with content and methods of teaching and evaluation is quintessential for the smooth workflow of teaching and learning process (Arkorful \& Abaidoo, 2015; Rahrouh et al., 2018). Lack of technical support services may become a trouble for the regular technical maintenance, and it cannot be satisfactorily carried out in time and moreover, the ICT and media tools can become malfunctioned and outdated. This will lead to the technical breakdowns of their electronic devices and hence the laboratories are always found to be at risk and needs to be maintained systematically. Hence regular check-up, service and maintenance of the devices need to be carried out to scrutinize their proper functions for real time experiment and observations.

\section{ONLINE LEARNING RESOURCES AND REFORM}

Being online education is much owed to the constructivist approach to teaching and learning, both the teachers and students are the rampant users of online content and media. They import their learning resources through surfing the internet. They focus on their relevant topic and content and discuss online to groom their acquired knowledge and insight on the subject they are interested. Several online free courses, webinars, interactive discussion forums are conducted to virtually engage the students to procure sufficient learning and expertise in their specific areas of interest. As digital learning encompasses knowledge and skills management, online courses need to be specifically designed to integrate all those concepts and practices in their module based presentations. With a sheer constructivist approach to enhance knowledge and skills based learning through technology, online courses can be aimed at to provide learning resources with both audio and video materials where the students can virtually listen, watch and follow-up the algorithms, pictorial designs and graphs with the added instructional guidelines from their teachers.

Online learning can be successfully accomplished by the collaborative efforts of both teachers and students as they correspond with one another with intellectual and emotional understanding and responsibility with much personal and social impulse to inform and practice their subjects. Online education can stand the test of times, if both the teachers and students communicate regularly and inform students' involvement and progress of the institutional management and the parents. The institutional support and administration remains a prerequisite in proper planning, implementation and execution of the curriculum and should offer guidance and provisions as it deemed necessary in the accomplishment of the courses conducted through online. While enrolled in an online course, students expect mutual interaction with the teachers and hence the teachers' role in responding immediately to them and communicating course requirements are most important to keep their morale of instruction even in virtual mode (Lauran et al., 2014). The success of the online education relies on keeping the stakeholders' confidence in immediate interconnection through Internet, Email, and WhatsApp messages.

The disruption of communication due to server problems or communication breakdown due to low interconnectivity problems is the most apparent technical barrier that any stakeholder or the user of digital technologies can experience. This needs to be immediately sorted out at the central level of the institute. And again, frequent cut off of the power supply throughout the country needs to be controlled as the government should take initiatives to provide uninterrupted power supply to the people. No student should be found anxious with grief over the frequent power cut and their inability to attend the long online classes or while taking up examinations. And to attend the extended sessions of their online classes in the long interrupted power supply cuts, most students drain up their battery and data and are unable to get into the subsequent online sessions of the day. This proves to be 
a severe blow to those students who are not afforded to purchase power bank or increase their data plan due to their prolonging financial crisis.

\section{CONCLUSIONS}

The adaptability and affordability of students to seek internet connection and engage in online learning is purely a matter of financial liabilities and it affects their privilege to enroll in online education. Hence, when we are quickly marching towards making digitalization in every walk of our life, and very specific in education, the government should intervene and redress the immediate concerns of the students that hinder them to participate in digital learning. It should take adequate measures that irrespective of students hailing from diverse backgrounds and different far off reaching places, uninterrupted power supply and internet connection should be provided. In this way, the ease and affordable access of internet connectivity will boost both the students of urban and remote alike and would voice for tremendous revolution and reforms in the making of the digitalization of education.

Funding: Author received no financial support for the research and/or authorship of this article.

Declaration of interest: Author declares no competing interest.

Data availability: Data generated or analysed during this study are available from the author on request.

\section{REFERENCES}

Aithal, P. S., \& Aithal, S. (2016). Impact of on-line education on higher education system. International Journal of Engineering Research and Modern Education, 1(1), 225-235. https://doi.org/10.5281/ zenodo. 161113

Albirini, A. (2006). Teachers' attitudes toward information and communication technologies: The case of Syrian EFL teachers. Computers \& Education, 47(4), 373-398. https://doi.org/10.1016/ j.compedu.2004.10.013

Almaiah, M. A., Alamri, M. M., \& Al-Rahmi, W. (2019). Applying the UTAUT model to explain the students' acceptance of mobile learning system in higher education. IEEE Access, 7(1), 174673174686. https://doi.org/10.1109/ACCESS.2019.2957206

Arkorful, V., \& Abaidoo, N. (2015). The role of e-learning, advantages and disadvantages of its adoption in higher education. International Journal of Instructional Technology and Distance Learning, 12(1), $397-$ 410.

Baporikar, N. (2016). Technology integration and innovation during reflective teaching. International Journal of Information and Communication Technology Education, 12(2), 14-22. https://doi.org/10.4018/IJICTE.2016040102

Bingimlas, K. A. (2009). Barriers to the successful integration of ICT in teaching and learning environments: A review of the literature. Eurasia Journal of Mathematics, Science and Technology Education, 5(3), 235-245. https://doi.org/10.12973/ejmste/75275

Bonvillian, W. B., \& Singer, S. R. (2013). The online challenge to higher education. Issues in Science and Technology, 29(4), 1-15.

Chang, V. (2016). Review and discussion: E-learning for academia and industry. International Journal of Information Management, 36(3), 476485. https://doi.org/10.1016/j.ijinfomgt.2015.12.007
Delamonica, E., Mehrotra, S., \& Vandemoortele, J. (2004). Education for all: How much will it cost? Development and Change, 35(1), 3-30. https://doi.org/10.1111/j.1467-7660.2004.00340.x

Dumford, A. D., \& Miller, A. L. (2018). Online learning in higher education: exploring advantages and disadvantages for engagement. Journal of Computing in Higher Education, 30(3), 452465. https://doi.org/10.1007/s12528-018-9179-z

Ertmer, P. A. (2005). Teacher pedagogical beliefs: The final frontier in our quest for technology integration. Educational Technology Research and Development, 53, 25-39. https://doi.org/10.1007/ BF02504683

Gautam, S. S., \& Tiwari, M. K. (2016). Components and benefits of elearning system. International Research Journal of Computer Science, 3(1), 14-17.

Ghavifekr, S., \& Rosdy, W. A. W. (2015). Teaching and learning with technology: Effectiveness of ICT integration in schools. International Journal of Research in Education and Science, 1(2), 175191. https://doi.org/10.21890/ijres.23596

Islam, N., Beer, M., \& Slack, F. (2015). E-learning challenges faced by academics in higher education: A literature review. Journal of Education and Training Studies, 3(5), 102-112. https://doi.org/10.11114/jets.v3i5.947

Keller, C., \& Cernerud, L. (2002). Students' perception of e-learning in university education. Learning, Media and Technology, 27(1-2), 5567. https://doi.org/10.1080/1358165020270105

Kocur, D., \& Kosc, P. (2009). E-learning implementation in higher education. Acta_ElectrotechnicaetInformatica, 9(1), 20-26.

Lauran, J. E., Samsuri, N. N., Nadzri, F. A., \& Rom, K. B. M. (2014). A Study on the student's perspective on the effectiveness of using elearning. Procedia-Social and Behavioural Sciences, 123, 139-144. https://doi.org/10.1016/j.sbspro.2014.01.1407

Love, N., \& Fry, N. (2006). Accounting students' perceptions of a virtual learning environment: Springboard or safety net? Accounting Education: An International Journal, 15 (2), 151-166. https://doi.org/10.1080/06939280600609201

Martin, R. (2007). Online education and training: Well-founded pedagogy or state corporate interest? South African Journal of Higher Education, 21(3), 473-484. https://doi.org/10.4314/sajhe.v21i3. 25718

Meskhi, B., Ponomareva, S., \& Ugnich, E. (2019). E-Learning in higher inclusive education: Needs, opportunities and limitations. International Journal of Educational Management, 33(3), 424-437. https://doi.org/10.1108/IJEM-09-2018-0282

Muruthy, A. E., \& Yamin, F. M. (2017). The perception and effectiveness of learning management system (LMS) usage among the higher education students. Journal of Technology and Operations Management, 12(1), 86-98. https://doi.org/10.32890/jtom2017.12. 1.10

Owusu-Fordjour, C., Koomson, C. K., \& Hanson, D. (2020). The impact of COVID-19 on learning: The perspective of the Ghanaian student. European Journal of Education Studies, 7(13), 88-101. https://doi.org/10.5281/zenodo.3753586 
Rahrouh, M., Taleb, N., \& Mohamed, E. A. (2018). Evaluating the usefulness of e-learning management system delivery in higher education. International Journal of Economics and Business Research, 16(2), 162-181. https://doi.org/10.1504/IJEBR.2018.094010

Sarkar, S. (2012). The role of information and communication technology (ICT) in higher education for the 21 st century. The Science Probe, 1(1), 30-40.

Sarrab, M., Al-Shihi, H., \& Rehman, O. M. H. (2013). Exploring major challenges and benefits of M-learning adoption. British Journal of Applied Science and Technology, 3(4), 826-839. https://doi.org/10.9734/BJAST/2013/3766

Schoepp, K. (2005). Barriers to technology integration in a technologyrich environment. Learning and Teaching in Higher Education: Gulf Perspectives, 2(1), 56-79. https://doi.org/10.18538/lthe.v2.n1.02
Sife, A. S., Lwoga, E. T., \& Sanga, C. (2007). New technologies for teaching and learning: Challenges for higher learning institutions in developing countries. International Journal of Education and Development Using ICT, 3(2), 57-67.

Songkram, N., Khlaisang, J., Puthaseranee, B., \& Likhitdamrongkiat, M. (2015). E-learning system to enhance cognitive skills for learners in higher education. Procedia-Social and Behavioral Sciences, 174, $667-$ 673. https://doi.org/10.1016/j.sbspro.2015.01.599

Sweeney, J., O'Donoghue, T., \& Whitehead, C. (2004). Traditional faceto-face and web-based tutorials: A study of university students' perspectives on the roles of tutorial participants. Teaching in Higher Education, 9(3), 311-323. https://doi.org/10.1080/1356251042000 216633 